\title{
O cuidado em saúde mental na atenção básica: uma cartografia
}

\author{
Mental health care in primary care: a cartography \\ El cuidado en salud mental en la atención básica: una cartografía
}

\author{
Taís Fernanda Maimoni Contieri Santana'; Maria Alice Ornellas Pereira"
}

\begin{abstract}
RESUMO
Objetivo: cartografar o cotidiano do cuidado ao portador de transtorno psíquico, tendo como sujeitos os profissionais de uma unidade de saúde da família, bem como os de um núcleo de apoio à saúde da família. Método: investigação de natureza qualitativa, com participação de nove profissionais, do noroeste paulista em meados de 2013. Utilizou-se para coleta de dados o estudo de caso, o diário de campo, a entrevista semiestruturada e o fluxograma analisador. O projeto foi aprovado por Comitê de Ética em Pesquisa. Resultados: foram apreendidos e estruturados em três territórios, sendo, neste estudo, apresentado o território do fazer; evidenciaram-se dificuldades à possibilidade da reversão do cuidado, este embasado, ainda, no modelo médico hegemônico. Conclusão: houve entraves para a efetivação do vínculo, da responsabilização e do comprometimento desses profissionais para vislumbrarem avanços no cotidiano das práticas em saúde mental, o que dificulta a reabilitação psicossocial.
\end{abstract}

Descritores: Atenção primária a saúde; cartografia; cuidado; saúde mental

\section{ABSTRACT}

Objective: to map the daily care of patients with psychic disorders, the subjects of the mapping being the personnel of a family health unit and a family health support unit. Method: nine health professionals participated in this qualitative study in northwest São Paulo in mid-2013. Data were collected by case study, field diary, semi-structured interview and analytical flowchart. The project was approved by the research ethics committee. Results: results were captured and structured in three territories, of which the territory of doing was presented in this study. These evidenced the difficulties facing possible reversal of care, which is still based on the hegemonic medical model. Conclusion: there were obstacles to effective bonding, accountability and commitment by these professionals, making it hard to envisage advances in daily mental health practice, which hinders psychosocial rehabilitation.

Descriptors: Primary health care ; geographic mapping; empathy; mental health.

\section{RESUMEN}

Objetivo: cartografiar el cotidiano del cuidado al portador del trastorno psíquico, los sujetos siendo los profesionales de una unidad de la salud de la familia, así como los de un núcleo de apoyo a la salud de la familia. Método: investigación de naturaleza cualitativa, con la participación de nueve profesionales, del noroeste de São Paulo, a mediados de 2013. Para la recolección de datos se utilizó el estudio de caso, el diario de campo, la entrevista semiestructurada y el diagrama de flujo analizador. El proyecto fue aprobado por el Comité de Ética en Investigación. Resultados: fueron delimitados y estructurados en tres territorios, siendo que, en este estudio, se presentó el territorio del hacer. Se evidenciaron dificultades en cuanto a la posibilidad de reversión del cuidado, con base aún en el modelo médico hegemónico. Conclusión: hubo obstáculos en cuanto a volver efectivos el vínculo, la responsabilidad y el comprometimiento por parte de esos profesionales para poder vislumbrar avances en el cotidiano de las prácticas en la salud mental, lo que dificulta la rehabilitación psicosocial.

Descriptores: Atención primaria de salud; mapeo geográfico; empatía; salud mental.

\section{INTRODUÇÃo}

A busca pela melhoria da atenção à saúde no país vem, ao longo de décadas, imprimindo um percurso caracterizado por enfrentamentos, desafios e avanços. Nessa dinâmica, a estratégia saúde da família (ESF) vem colaborar, pois esse modelo de atuação prioriza a atenção básica à saúde, como alternativa à estratégia centrada exclusivamente na doença, permitindo a gestores, profissionais e usuários do Sistema Único de Saúde
(SUS) compreender a dinâmica dos lugares e dos sujeitos (individual e coletivo), desvelando as desigualdades sociais e as iniquidades em saúde, principalmente no campo da saúde mental ${ }^{1}$.

A reforma psiquiátrica brasileira tem como ponto forte a desinstitucionalização que se revela como um processo social complexo, envolvendo todos os atores sociais; visa modificar a forma de organização das ins- 
tituições psiquiátricas, criando estruturas que venham substituí-las. É um processo em movimento, dinâmico, que requer mudanças nos modelos de atenção à saúde, envolve assistência à família, visa à reinserção da pessoa na sociedade e busca a reabilitação psicossocial. Expressa o exercício pleno da cidadania, com vistas a melhorar o poder de contratualidade das pessoas nos três grandes cenários: habitat, rede social e trabalho com valor social².

O presente estudo remete à indagação: Como a ESF vem contemplando o cuidar em saúde mental na comunidade?

Diante ao exposto, esta pesquisa teve por objetivo cartografar o cotidiano do cuidado ao portador de transtorno psíquico, tendo como sujeitos os profissionais da saúde de uma ESF, bem como os de um Núcleo de Apoio a Saúde da Família (NASF).

\section{REVISÃo DE LITERATURA}

O pensar no campo psicossocial remete às práticas de reinserção e permanência do sujeito no convívio social, o que exige articulação da atenção básica com as novas propostas dos serviços substitutivos à hospitalização psiquiátrica ${ }^{3}$. Ao se considerar a abrangência do processo de transformação da assistência psiquiátrica, reitera-se que o tratamento e a instituição do cuidado deixam de significar apenas a prescrição de medicamentos e a aplicação de terapias, para ocuparem-se dos sujeitos e não apenas da doença, sendo a ESF, um dispositivo relevante nesse contexto.

Vale ressaltar que a Organização Mundial da Saúde (OMS) apontou a importância da integração de ações de saúde mental na atenção primária, ao recomendar, ao território, à comunidade e às redes de serviços de saúde, que se organizassem, de forma a reconhecerem que a atenção à saúde mental é parte dos cuidados primários de saúde, com ênfase nas novas formas de cuidar ${ }^{4}$.

Ao revelarem-se as nuances do cuidado na ESF, destaca-se que a principal mudança é que o cuidado deixa de ser centrado no indivíduo e na doença, passando também para o coletivo, sendo a família o espaço privilegiado de atuação ${ }^{5}$.

Enfatizando esse aspecto do cuidar, ressalta-se que os usuários, como portadores e fabricantes das necessidades de saúde são complexos, têm modos qualitativos de viver, são coletivos expostos a riscos, necessitam de encontros vinculantes e acolhedores, têm tensões entre autonomia e heteronomia, possuem desejos, como também são constituídos de corpos biológicos ${ }^{6}$.

Destarte, considerando a ESF no cenário do elenco dos serviços, e especificamente, na atenção à saúde mental da população assistida, pode-se afirmar que esse território é considerado importante espaço de cuidado, uma vez que as equipes de saúde da família se constituem em poderosas ferramentas para a oferta de cuidado integral à saúde e representam recursos essen- ciais para a assistência à saúde mental na comunidade, contribuindo com a identificação precoce e a viabilidade de tratamento, como também para a redução do estigma relacionado aos pacientes com transtorno mental ${ }^{7}$.

Esta pesquisa apoia-se nos preceitos de cuidado ${ }^{6}$, este embasado nas relações entre trabalhadores e usuários que perpassa pelas tecnologias leves, bem como nas obras que sustentam a discussão pertinente à reabilitação psicossocial $^{2,3}$, construindo contratos sociais, que permitem ao usuário subverter o processo de reclusão, que é resultado dos efeitos da doença mental e da exclusão social.

\section{Metodologia}

Foi realizada pesquisa qualitativa, mediante estudo de caso observacional, com utilização de diário de campo, entrevista individual semiestruturada e fluxograma analisador. O estudo de caso cujo objeto é uma unidade que se analisa profundamente ${ }^{8}$, foi pautado no o cotidiano de cuidados em saúde mental na ESF; o trabalho de campo buscou a aproximação com os sujeitos e forneceu elementos do seu cotidiano.

O projeto seguiu a Resolução no 466/2012, do Conselho Nacional de Saúde, sendo avalido e aprovado pelo Comitê de Ética em Pesquisa da Faculdade de Medicina de Botucatu (UNESP), sob protocolo nํ 42042012. Os participantes aceitaram colaborar com este estudo, assinando o Termo de Consentimento Livre e Esclarecido. Foram garantidos o sigilo e o anonimato das identidades, sendo utilizado para tal o código (E) para cada entrevistado, seguindo uma sequência numérica.

O campo de pesquisa foi uma unidade de ESF do interior de São Paulo, pertecente à divisão regional de saúde (DRS) VI, composta por uma equipe mínima de profissionais e que conta com a retaguarda de um NASF I. O estudo foi desenvolvido em meados de 2013.

Participaram nove profissionais, sendo sete que desempenham atividades na ESF: um enfermeiro, uma técnica de enfermagem, cinco agentes comunitários de saúde (ACS), todos concursados e com mínimo de dois anos na função; como também, dois integrantes da equipe do NASF: uma enfermeira e uma psicóloga. Em relação aos profissionais do NASF, a enfermeira atua na enfermagem há 25 anos, além de desenvolver consultoria a esse Núcleo; atualmente, também dirige um serviço de saúde mental do município vizinho; a psicóloga foi contratada recentemente.

As questões do roteiro de entrevista referem-se aos cuidados desempenhados pelos sujeitos e constaram dos seguintes itens; como a equipe presta o cuidado em saúde mental? Como se estabelece a relação equipe-usuário-comunidade? Que benefícios proporciona e quais dificuldades encontra? Após as entrevistas, em comum acordo com os participantes, foi agendada uma reunião com o objetivo de elaborar o fluxograma. Este foi um instrumento importante para a construção 
da análise do material trazido, uma vez que auxiliou no entendimento do percurso do usuário na unidade, desde sua entrada até a saída9 .

Considerou-se a partir daí o caso traçador, sendo este um método que permitiu avaliar o processo de trabalho da equipe, reconstituindo um caso, possibilitando melhor observação do ato de cuidar; também permitiu traduzir para um formato que fosse visível e partilhável por todos, o processo do trabalho coletivo ${ }^{10}$. Na perspectiva de compreender a realidade do serviço, tendo como foco o cuidado à pessoa acometida pelo transtorno mental, a cartografia se fez necessária, sendo esta um método que visa acompanhar um processo, e não representar um objeto ${ }^{9}$.

Os processos de trabalho analisados por ferramentas cartográficas possibilitam captar o trabalho vivo, dinâmico, permitindo ao cartógrafo por meio do olho vibrátil, perceber a produção no campo da saúde a partir de suas intensidades e afetamentos ${ }^{11}$. A cartografia surge como um modo de acompanhar percursos, percebendo as conexões de redes ou rizomas, possibilitando a construção de mapas ${ }^{12}$.

\section{RESULTADOS E DISCUSSÃO}

As entrevistas, o diário de campo e o fluxograma foram examinados e, após, foram extraídos seus conteúdos, para a análise. No processo de elaboração do estudo, foi percebido que os movimentos dinâmicos pulsantes na instituição são oriundos do cotidiano do trabalho, ganhavam formas e contornos, assim como, os movimentos contínuos de territorialização, desterritorialização e reterritorialização se faziam presentes. 0 fluxograma analisador revelou, através da fala da equipe, o caminho percorrido por uma paciente portadora de transtorno psíquico, desde sua entrada na unidade, bem como os cuidados ofertados e sua saída.

\section{Descrição do fluxograma analisador}

Iniciou-se com a equipe elegendo um caso traçador, o que possibilitou visualizar o caminho percorrido por uma paciente que recebeu o nome fictício de Vitória. Esta contava com 30 anos e um diagnóstico de esquizofrenia; era usuária do centro de atenção psicossocial (CAPS) de referência da unidade ESF, e tinha histórico de várias internações em instituições psiquiátricas, sendo vítima de exclusão, preconceito e abuso sexual pelo pai. Ver Figura 1.

Na sequência da elaboração do fluxograma, os participantes narraram e discutiram sobre o percurso de Vitória na unidade, assim como refletiram acerca da organização do processo de trabalho executado.

\section{Entrada}

A recepção era feita pela técnica de enfermagem (TE), juntamente com os ACS. Considerando que o acolhimento da pessoa na unidade é fator importante, foi ouvido o relato:

[...]quero que eles saibam que podem contar comigo, mesmo quando não é da minha alçada. Acho que eles confiam no meu trabalho. (E1)

A ESF é a única unidade de saúde no bairro e possui núcleos familiares que vivem em situações precárias do ponto de vista econômico e social. Focando a situação de Vitória, a usuária tem livre acesso aos profissionais, ela sempre os procurou durante suas crises. Na reunião que derivou o fluxograma, o ACS se colocou como o elo entre a unidade e a micro área onde reside a usuária. Vitória sempre perambulou pelas ruas, procurando alimento e afeto e, por muitas vezes, pernoitou fora de casa.

\section{Cardápio}

$\mathrm{Na}$ ESF o atendimento consistia em consulta médica (clínica geral), com prescrição de psicotrópico e encaminhamento ao CAPS I. Em período anterior à coleta de dados deste estudo, havia reuniões em grupo e oficinas terapêuticas, porém, estas atividades não mais aconteceram.

A família era abordada e orientada pela equipe. Os profissionais da ESF eram convidados a participar de atividades no NASF, que incluiam capacitações e oficinas artesanais, nas quais se abordavam temas relacionados à saúde mental, principalmente sobre a reabilitação. $O$ artesanato, segundo a equipe, objetivava reduzir o ócio dos usuários, bem como levá-los a obter uma fonte de renda. Embora convidada, Vitória nunca participou dessas atividades. Os sujeitos relataram que Vitória, por diversas vezes, se deslocou até a residência dos profissionais da ESF e do NASF, buscando ajuda.

\section{O processo de decisão}

Os momentos decisórios eram os mais traumáticos, pois a equipe se sentia desprovida de recursos para tomar atitudes, como falta de conhecimento sobre o que pensar e como agir. A partir do diagnóstico médico de transtorno psíquico, a equipe da ESF recebia apoio matricial do NASF, estabelecendo protocolos de atendimento. Os casos considerados críticos eram encaminhados ao CAPS I do município vizinho, uma vez que a cidade onde está localizada a ESF pesquisada não possuia o referido serviço.

A equipe conclui que a melhor decisão para a situação de Vitória era a internação, referida como lar, já que a família nuclear não a aceitava e pela equipe considerar que as crises ocorridas, eram desencadeadas pelo uso irregular dos psicotrópicos. Iniciou-se, então, nova proposta de cuidado que julgaram a mais sensata: lutar para que Vitória conseguisse a internação. Nessa mesma época, as crises se agravavam. Assim, a equipe considerou que o melhor lugar para acolhê-la, seria o hospital psiquiátrico da cidade vizinha. 
Saída

A saída de um usuário é vivenciada pela equipe, quando há melhora de um quadro ligado aos aspectos orgânicos ou associado aos transtornos mentais. Esse foi o momento encarado pelo grupo como de realização e satisfação de um dever cumprido. Vitória encontrava-se asilada em um hospital psiquiátrico, há mais de um ano, sendo medicada e, segundo a equipe, fora da crise. Conforme o relatado, Vitória conseguia, no hospital, participar de grupos terapêuticos e oficinas artesanais, conversava sem agressividade, os sintomas psíquicos diminuíram e o asseio corporal era constante.

Na elaboração do material a ser analisado, considerou-se o estabelecimento dos territórios ${ }^{13}$, seguiu-se

Usuária: Vitória procura ajuda na ESF

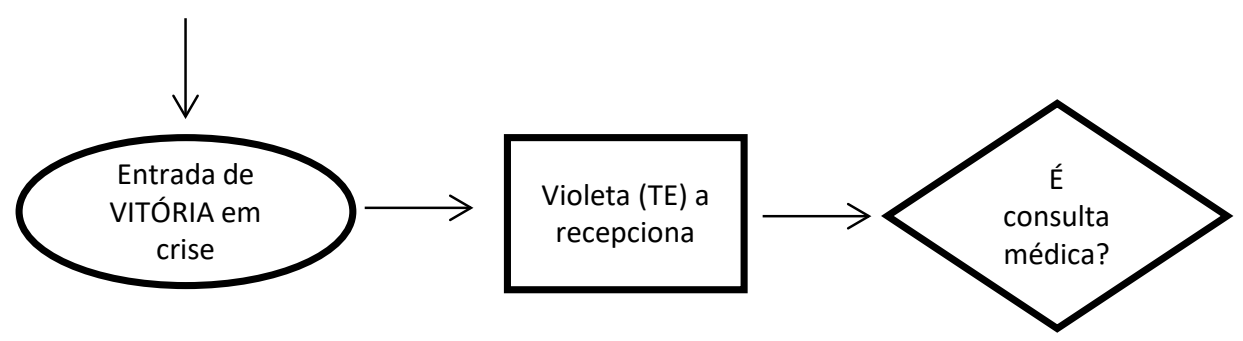

Sim
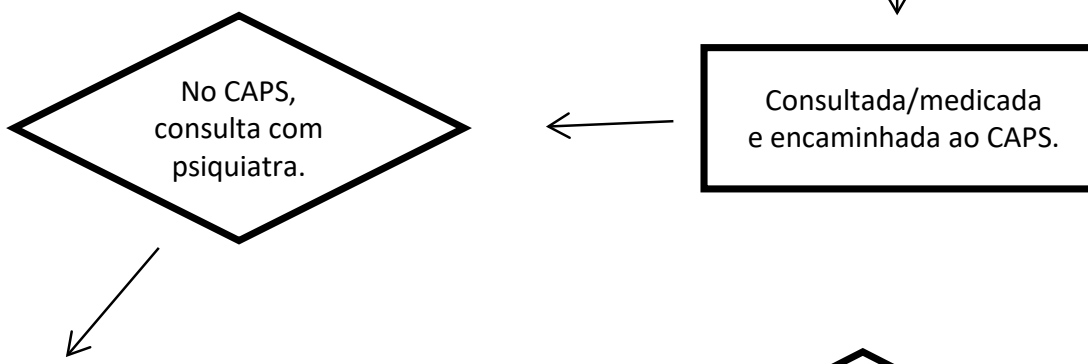

Prescrição de psicotrópicos e agendamento de retorno.
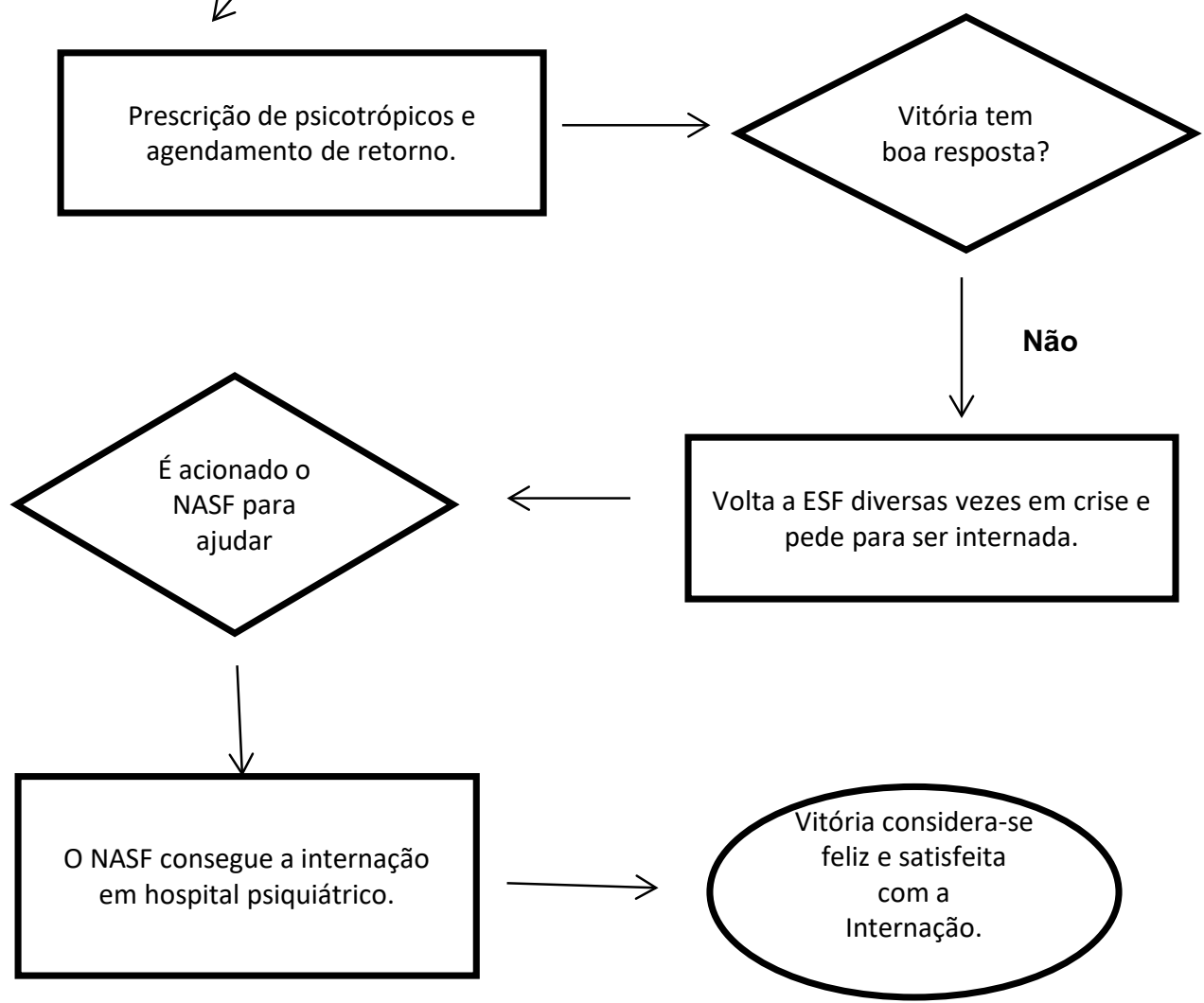

FIGURA 1: Fluxograma analisador do cuidado a uma usuária com transtorno psíquico. ESF, Cafelândia/SP. 
o acompanhamento da realidade experienciada pelos sujeitos. Instaurou-se uma relação onde pesquisador-cartógrafo e território de pesquisa se constituíam no mesmo processo, indagando-se os sentidos dos movimentos que se produziam no ato de pesquisar, expressando as suas singularidades ${ }^{14}$.

Trabalhar com o território é apostar na criação de alternativas de cuidado, dirigindo o olhar para onde as pessoas vivem e se relacionam e o quanto esses lugares mostram suas singularidades, diversidades e realidades, concepções essenciais para o cuidado no campo psicossocial ${ }^{15}$. Desse modo, ao objetivar a cartografia do cuidado prestado pelos profissionais, foram considerados o território do fazer, do pensar o fazer e dos desafios encontrados. Neste artigo, que é fragmento de uma investigação maior, produto de uma dissertação de mestrado, foi abordado apenas o território do fazer.

Durante a elaboração deste estudo, acompanhou-se a dinâmica dos profissionais, observando o trabalhar em equipe, com grande participação do ACS. O trabalho em equipe na ESF é imprescindível para que se possam cumprir as seguintes atribuições comuns a todos os profissionais: realizar o cuidado em saúde e responsabilizar-se pela população adscrita; entre as ações do ACS destacam-se: a escuta qualificada, exercendo um papel de educador, por meio de visitas domiciliares e o acolhimento das necessidades das famílias atendidas, levantando também as vulnerabilidades sociais e de saúde dessas famílias ${ }^{1}$.

No processo da assistência, o ACS é figura ímpar no primeiro contato equipe-comunidade, sendo, então, responsável pelo elo e vínculo, uma vez que, como morador e componente desse território explorado pelas ferramentas cartográficas ${ }^{16}$, também é protagonista dessa realidade.

O vínculo é, contudo, um fenômeno que envolve duas pessoas em cada relação e é influenciado pelas vinculações vivenciadas anteriormente por elas ${ }^{17}$. A paciente, representada no fluxograma, vinha de uma família humilde, com poucos recursos e um histórico de transtornos psíquicos de mãe e irmãos. Nesse lar as brigas eram constantes, a família a rejeitava, fazendo-a por diversas vezes dormir em um colchão na varanda da casa. Esta situação era presenciada pela equipe da ESF, quando a visitava para entregar-lhe os remédios (psicotrópicos). Os relatos elaborados pelos profissionais durante as entrevistas, mencionam a dificuldade da formação do vínculo no que se refere à saúde mental:

[...]é bem difícil aqui, os pacientes procuram nosso serviço em busca de ajuda e muitas vezes não podemos ajudá-los. Quando vamos às casas, também não sabemos, algumas vezes, como agir. A família não colabora, é difícil [...] (E2)

A criação de vínculos entre cada usuário e uma equipe ou um profissional representa a possibilidade de espaços de trocas, necessárias ao cuidado em saúde mental As ações em saúde mental são assumidas no cotidiano, emergindo com sensibilidade, responsabilidade, acolhimento e escuta qualificada e devem valorizar como esses sentidos influenciam no cuidado prestado e no lugar que cada um, profissional e usuário, ocupam na relação ${ }^{18}$. O cardápio inicial de Vitória, como dos outros portadores de transtornos psíquicos que recorreram à unidade, era sempre permeado pela consulta médica e medicalização, como observa-se na seguinte fala:

[...]o cuidado que vem aqui para nós é o seguinte: o paciente vem com esse problema, a gente marca consulta para a médica, ele passa com a médica, onde a mesma é clinica geral, que medica e encaminha para CAPS, certo? [...] (E1)

Assim, assistência à saúde mental, no contexto do estudo, se confunde ou até mesmo se limita, a produção de consultas e exames. Continuando o percurso de Vitória, segundo o relato da equipe, suas idas à ESF tornaram-se frequentes, de modo que, ao se aproximar do portão de entrada do serviço, os profissionais ficavam apreensivos, pois não previam se ela estava em crise ou não. Consultando seu prontuário, constataram-se registros de cinco internações (interdição com pedido cautelar) em hospital psiquiátrico com permanência média de 30 dias, e, nos relatórios de alta, sempre constava melhora do quadro clínico.

O modelo de tratamento baseado em instituições manicomiais ou asilares tem sido discutido, criticado e negado nas últimas décadas, pois efetivamente tal paradigma gera a exclusão e o depósito de pessoas nessas instituições. No entanto, num salto histórico, ainda estão presentes limitações no tratamento e no cuidado ${ }^{19}$. Os contatos, durante o transcorrer da pesquisa e as anotações do diário de campo, evidenciam relatos de que, naquela unidade, não havia o que fazer em relação ao tratamento de pessoas com transtornos mentais:

[...]aqui não tem um lugar próprio e conclusão, você não vê melhora! (E1)

[...]no município, não temos serviço próprio, temos que encaminhar para centros especializados [...] (E3)

E ainda, percebe-se a dificuldade de compreender/definir o transtorno psíquico:

[...]antigamente, a gente tinha aqui do lado os alcoólicos anônimos, muitas pessoas os procuravam, a gente sabia quem eram, tinham problemas mentais também. O pessoal da comunidade não sabia que eles tinham problemas, pois há doentes mentais que são aparentemente normais, então eu acho que tinha que ter um lugar específico para esse tipo de atendimento[...] (E4)

Desvela-se a fragilidade da equipe no contexto do cuidado, os sentimentos são múltiplos, a necessidade de fazer algo se mistura com a impotência que ata. A equipe parecia não definir o conceito de reabilitação no cotidiano do cuidado, sentia-se desprovida de recursos, como também da necessidade de um lugar especializado para o cuidado em saúde mental.

Nesse momento, declarava-se a fragilidade do cuidado, rompia-se a contratualidade e a responsabilização, bem 
como as relações de vínculo e acolhimento, reforçava-se a necessidade das tecnologias leves ${ }^{7}$. Para a efetividade das ações estabelecidas nas equipes da ESF, inclusive para que a atenção à saúde mental se incorpore nas práticas cotidianas, há que se ampliar os saberes clínicos e epidemiológicos, não se restringindo a diagnósticos e medicações; a atuação mais incisiva é relevante, deve ter como enfoque a singularidade da assistência, rompendo a forte tendência à observação do modelo biomédico como norma para o estabelecimento do cuidado ${ }^{20}$.

A reabilitação, como estratégia, possibilita a recuperação da capacidade de gerar sentido; assim, a tarefa do serviço de saúde mental é a de ajudar a pessoa que, em algum momento de sua vida, perdeu a capacidade de gerar sentido, acompanhando-a na recuperação de espaços não protegidos, mas socialmente abertos para a produção de novos sentidos².

A equipe da ESF vê a necessidade de investimentos para ampliar o cuidado em saúde mental.

[...]então, precisamos de um automóvel, de profissionais capacitados, de um local, não apenas estrutura física, mas que eles pudessem desenvolver atividades, para que eles pudessem conversar com os profissionais[...] (E2)

Nos serviços, a assistência prestada, os recursos físicos e materiais, as características organizativas e o tipo de trabalho da equipe são considerados variáveis importantes na evolução do transtorno mental, que devem ser somados aos os recursos individuais do paciente e do contexto, em que está inserido, pois desempenham um papel fundamental no sucesso ou fracasso de um tratamento.

Afirmando a importância do contexto e da complexidade dos clientes, que não podem mais ser reduzidos a uma categoria diagnóstica, constata-se uma relevante inversão na lógica de pensar os tratamentos ao sugerir a adoção de uma práxis, que ao reconhecer os recursos de cada pessoa, assuma o papel de acompanhá-la na construção de espaços de negociação e de resgate da cidadania ${ }^{20}$.

Dessa forma, espera-se superar as dificuldades na organização do trabalho em equipe, ampliar a clínica com centralidade no sujeito e ir além da atenção tradicional, cujo funcionamento é burocratizado e médico-centrado ${ }^{21}$.

A equipe deve compreender o sujeito em sofrimento psíquico, considerando suas demandas e necessidades apresentadas. A singularidade se produz diante de forças como as enfermidades, os anseios e os interesses, assim como o trabalho, a cultura, a família e a rede social.

\section{CONCLUSÃO}

A partir da cartografia do cuidado na ESF, foi possível compreender que os profissionais dos serviços comunitários passam a ser, cada vez mais, os principais provedores de cuidados em saúde mental. A cartografia possibilitou captar as dificuldades inerentes à possibilidade de reversão do modelo hegemônico proposto pelas políticas públicas, bem como à efetivação dos princípios do SUS.
Percebeu-se, ainda, que os profissionais apresentavam sentimentos de impotência, angústia, sofrimento e tensão frente à execução de cuidados em nível de saúde mental, bem como se eximiam do cuidado, delegando-o a outras esferas, negando sua responsabilização.

Frente aos resultados apresentados, recomenda-se à equipe repensar a resolubilidade das ações em saúde, no que tange ao vínculo, à coparticipação e ao comprometimento. É preciso prevalecer as prerrogativas pertinentes à reabilitação psicossocial e favorecer a participação dos profissionais no trabalho em equipe multiprofissional e interdisciplinar, reforçando a produção do cuidado humanizado e proporcionando modos de intervenções mais adequadas às reais necessidades do portador de transtorno psíquico.

\section{REFERÊNCIAS}

1. Gondim GMM, Monken M. Territorialização em saúde. Rio de Janeiro, Escola Nacional de Saúde Pública, Fundação Osvaldo Cruz; [Internet] 2012 [citado em 20 set 2017]. Disponível em: http:// www.epsjv.fiocruz.br/upload/ArtCient/25.pdf

2. Saraceno B. Libertando identidades: da reabilitação psicossocial à cidadania possível. Rio de Janeiro: Te Corá/Instituto Franco Basaglia; 2001.

3. Amarante P. Teoria e crítica em saúde mental - escritos selecionados. Rio de Janeiro: Zagodon; 2015.

4. Wenceslau LD, Ortega F. Saúde mental na atenção primária e saúde mental global: perspectivas internacionais e cenário brasileiro. Interface (Botucatu) [Internet]. 2015 [citado em 20 set 2017]; 19(55):1121-1132. Disponível em: http://www.scielo. br/scielo.php?script=sci_arttext\&pid=S14143283201500040112 $1 \& \operatorname{lng}=$ en\&nrm=iso.

5. Câmara MC, Pereira MAO. Percepções de transtorno mental de usuários da Estratégia Saúde da Família. Rev. gaúch. enferm. 2010; 31(4): 730-7.

6. Merhy EE. Saúde: a cartografia do trabalho vivo. São Paulo: Hucitec; 2007.

7. Souza J, Almeida LY, Luis MAV, Nievas AF, Veloso TMC, Barbosa $\mathrm{SP}$, et al. Mental health in the Family Health Strategy as perceived by health professionals. Rev. bras. enferm. [Online]. 2017 [cited 2018 Sep 10] 70(5): 935-941. Available from: http://www. scielo.br/pdf/reben/v70n5/0034-7167-reben-70-05-0935.pdf

8. Merhy EE, Franco TB. Cartografias do trabalho e cuidado em saúde. Tempus: Actas de Saúde Coletiva [Internet]. 2012 [citado em 29 set 2017] (6):151-63 Disponível em: http://www.tempus. unb.br/index.php/tempus/article/viewFile/1120/1034

9. Kessner DM, Carolyn EK, James S. Assessing health quality-the case for tracers. New England Journal of Medicine [Internet]. 1973 [cited 2018 Jan 15] 288(4): 189-94. Available from: http://www. nejm.org/doi/pdf/10.1056/NEJM197301252880406

10. Kastrup $V$. O funcionamento da atenção no trabalho do cartógrafo. In: Passos E, Kastrup V, Escóssia L, organizadores. Cartografias e devires: a construção do presente. Porto Alegre (RS): Sulina; 2010.p.32-51

11. Franco TB, Magalhães Júnior HM. Integralidade na assistência à saúde: a organização das linhas do cuidado. In: Merhy EE, Magalhães Junior HM, Rimoli J, Franco TB, Bueno WS. O trabalho em saúde: olhando e experienciando o SUS no cotidiano. 4a ed. São Paulo: Hucitec; 2007. p.125-33

12. Kastrup V, Passos E. Cartografar é traçar um plano comum. Fractal: Revista de Psicologia. 2013; 25(2):263-80.

13. Gonçalves CAV, Machado AL. Cartografia do cotidiano de cuidados à pessoa com depressão. Sau. \& Transf. Soc. 2011; 1(3): 68-76. 14. Passos E, Kastrup V, Escossia L. Pistas do método da car- 
tografia: pesquisa-intervenção e produção de subjetividade. Porto Alegre: Sulina; 2015.

15. Silva AB, Pinho LB. Território e saúde mental: contribuições conceituais da geografia para o campo psicossocial. Rev. enferm. UERJ. 2015, [citado em 29 set 2017]; 23(3):420-4. Disponível em: http://www.facenf.uerj.br/v23n3/v23n3a21.pdf

16. Franco TB, Merhy EE. Atenção domiciliar na saúde suplementar: dispositivo da reestruturação produtiva. Ciênc. saúde coletiva (Online). 2008 [citado em 15 jan 2018]; (13)5:1511-20. Disponível em: http://www.scielo.br/scielo.php?script=sci_ arttext\&pid=S1413-81232008000500016\&lng=en\&nrm=iso.

17. Willrich JQ, Kantorski LP, Antonacci MH, Cortes JM, Chiavagatti FG. Da violência ao vínculo: construindo novos sentidos para a atenção à crise. Rev. bras. enferm. [Online]. 2014 [citado em 12 dez 2017]; 67(1):97-103. Disponível em: http://www.scielo.br/ pdf/reben/v67n1/0034-7167-reben-67-01-0097.pdf
18. Martines WRV, Machado AL. Produção de cuidado e subjetividade. Rev. bras. enferm. [Online] 2010 [cited 2017 Dec 12]; 63(2): 328-33 Available from: http://www.redalyc.org/articulo. oa?id $=267019594025$

19. Garcia APRF, Freitas MIP, Lamas JLT, Toledo VP. Nursing process in mental health: an integrative literature review. Rev. bras. enferm. [Online]. 2017 [cited 2017 Oct 15] . 70(1):209-18. Available from: http://www.scielo.br/pdf/reben/v70n1/0034-7167-reben-70-01-0220.pdf

20.Saraceno, B. Libertando identidades: da libertação psicosssocial à cidadania possível. Rio de Janeiro: Te Corá/ Instituto Franco Basaglia; 2001.

21. Corrêa VAF, Acioli S, Mello AS, Dias JR, Pereira RDM. Projeto terapêutico singular: reflexões para a enfermagem em saúde coletiva. Rev. enferm. UERJ. 2016 [citado em 29 set 2017] 24(6):e26309. Disponível em: http://www.facenf.uerj.br/v24n6/v24n6a02.pdf 